This item was submitted to Loughborough's Research Repository by the author.

Items in Figshare are protected by copyright, with all rights reserved, unless otherwise indicated.

\title{
D-m-D chromophores based on dithieno[3,2-b:2',3'-d]thiophene (DTT): Potential application in the fabrication of solar cell
}

PLEASE CITE THE PUBLISHED VERSION

http://dx.doi.org/10.1016/j.tet.2016.11.077

\section{PUBLISHER}

(C) Elsevier

\section{VERSION}

AM (Accepted Manuscript)

\section{PUBLISHER STATEMENT}

This work is made available according to the conditions of the Creative Commons Attribution-NonCommercialNoDerivatives 4.0 International (CC BY-NC-ND 4.0) licence. Full details of this licence are available at: https://creativecommons.org/licenses/by-nc-nd/4.0/

\section{LICENCE}

CC BY-NC-ND 4.0

\section{REPOSITORY RECORD}

Wang, Chuan-Zeng, Jung-Hee Do, Thamina Akther, Xing Feng, Lynne Horsburgh, Mark R.J. Elsegood, Carl Redshaw, and Takehiko Yamato. 2019. "D-m-d Chromophores Based on Dithieno[3,2-b:2',3'-d]thiophene (DTT): Potential Application in the Fabrication of Solar Cell". figshare. https://hdl.handle.net/2134/24348. 


\section{Graphical Abstract}

\section{D- $\pi$-D Chromophores based on Dithieno[3,2-b:2',3'-d]thiophene (DTT): Potential Application in the Fabrication of Solar Cell}

Leave this area blank for abstract info.

Chuan-Zeng Wang ${ }^{\mathrm{a}}$, Jung-Hee Do ${ }^{\mathrm{a}}$, Tahmina Akther ${ }^{\mathrm{a}}$, Feng Xing ${ }^{\mathrm{b}}$, Lynne Horsburgh ${ }^{\mathrm{c}}$, Mark R. J. Elsegood ${ }^{\mathrm{c}}$, Carl Redshaw $^{\mathrm{d}}$ and Takehiko Yamato ${ }^{\mathrm{a}, *}$

${ }^{a}$ Department of Applied Chemistry, Faculty of Science and Engineering, Saga University, Honjo-machi 1, Saga 840-8502 Japan, E-mail: yamatot@cc.saga-u.ac.jp.

${ }^{b}$ School of Printing and Packaging Engineering, Beijing Institute of Graphic Communication, 1 Xinghua Avenue (Band Two), Daxing, Beijing, 102600, P. R. China

${ }^{c}$ Chemistry Department, Loughborough University, Loughborough, LE11 3TU, UK

d Department of Chemistry, The University of Hull, Cottingham Road, Hull, Yorkshire, HU6 7RX, UK

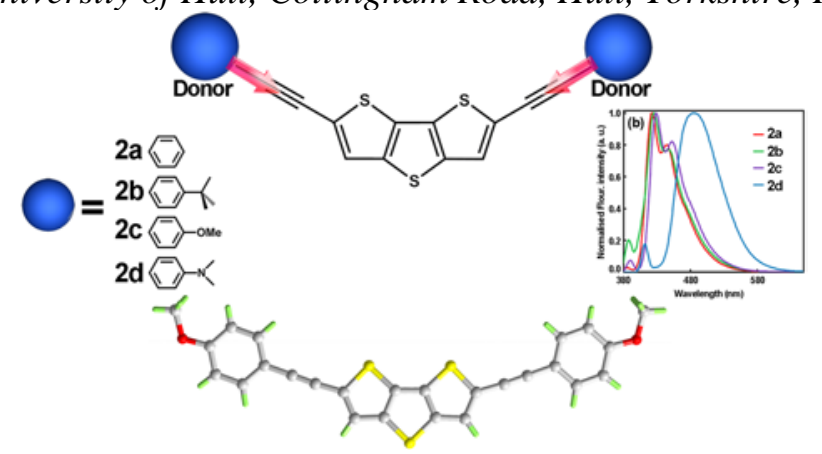


Tetrahedron

journal homepage: www.elsevier.com

\title{
D- $\pi$-D Chromophores based on Dithieno[3,2-b:2',3'-d]thiophene (DTT): Potential Application in the Fabrication of Solar Cell
}

\author{
Chuan-Zeng Wang ${ }^{\mathrm{a}}$, Jung-Hee Do ${ }^{\mathrm{a}}$, Tahmina Akther ${ }^{\mathrm{a}}$, Feng Xing ${ }^{\mathrm{b}}$, Lynne Horsburgh ${ }^{\mathrm{c}}$, Mark R. J. \\ Elsegood $^{\mathrm{c}}$, Carl Redshaw ${ }^{\mathrm{d}}$, Takehiko Yamato ${ }^{\mathrm{a}, *}$ \\ ${ }^{a}$ Department of Applied Chemistry, Faculty of Science and Engineering, Saga University, Honjo-machi 1, Saga 840-8502 Japan, E-mail: yamatot@cc.saga- \\ u.ac.jp. \\ ${ }^{b}$ School of Printing and Packaging Engineering, Beijing Institute of Graphic Communication, 1 Xinghua Avenue (Band Two), Daxing, Beijing, 102600, P. R. \\ China \\ ${ }^{c}$ Chemistry Department, Loughborough University, Loughborough, LE11 3TU, UK \\ ${ }^{d}$ Department of Chemistry, The University of Hull, Cottingham Road, Hull, Yorkshire, HU6 7RX, UK.
}

\section{ARTICLE INFO}

ABSTRACT
Article history:

Received

Received in revised form

Accepted

Available online

Keywords:

D- $\pi$-D chromophores

Dithieno[3,2-b:2',3'- $d]$ thiophene

Blue fluorescent

Photo-physical properties

Density Functional Theory
In this work, four stable dithieno[3,2-b:2',3'-d]thiophene-based $\pi$-extended molecules were designed and synthesized via a Pd-catalyzed Sonogashira coupling reaction. The structures of these symmetrical compounds, including dithieno[3,2-b:2',3'-d]thiophene (DTT) as the $\pi$-center and various donor (D) groups, were determined on the basis of NMR spectral data, elemental analysis, and X-ray crystallography. The photo-physical properties of the DTT-based derivatives 2 were fully investigated in both solution and solid state. The notable optical features of their solid-state powders showed significant red-shift in comparison with the luminescence of their dilute dichloromethane solutions. These results combined with the theoretical calculations indicate that they are promising candidates for the several applications in electronic and optoelectronic devices, as well as organic dyes for solar cells.

\section{Introduction}

Considerable attention has been paid to the development of oligothiophenes for use in organic solar cells, ${ }^{1-2} \pi$ conjugated conducting polymers, ${ }^{3-6}$ high-performance organic field-effect transistors (OFET), ${ }^{7-8}$ and organic lightemitting materials. $^{9-10}$ Generally, one of the strategies for fine-tuning the HOMO-LUMO gap involves the utilization of extended thiophene subunits ${ }^{11}$ and particularly those rigid structures possessing an extended $\pi$ - conjugation in the ground state, ${ }^{12}$ such as thienothiophenes (TTs) and dithienothiophenes (DTTs). Thiophenes can be obtained from thienoacenes that are effective for increasing the intermolecular interactions and adjusting the band gap of organic materials in the solid state. ${ }^{13-16}$

Dithieno[3,2-b:2',3'-d]thiophene (DTT) contains three annulated thiophene rings and is one of the six isomers of DTTs (dithieno[3,2- $\left.b ; 2^{\prime}, 3^{\prime}-d\right]$ thiophene, dithieno-[3,4$\left.b ; 3^{\prime}, 4^{\prime}-d\right]$ thiophene, dithieno[2,3- $\left.b ; 3^{\prime}, 2^{\prime}-d\right]$ thiophene, dithieno[2,3- $\left.b ; 2^{\prime}, 3^{\prime}-d\right]$ thiophene, dithieno[3,4- $b ; 3^{\prime}, 2^{\prime}-$ $d]$ thiophene, and dithieno[3,4- $\left.b ; 2^{\prime}, 3^{\prime}-d\right]$ thiophene) which have unique electronic properties due to their planar, conjugated, sulfur-rich, and highly thermally stable

\footnotetext{
* Corresponding author. Fax: +81 95228 8548; e-mail address: yamatot@cc.saga-u.ac.jp (T. Yamato).
}

structure. ${ }^{9,17-19}$ The first synthesis and spectroscopic assignments of DTT were reported in $1971 .^{20}$ The fused structure of DTT can promote $\pi$-stacking which is predicted to be a favourable motif for high charge transport in devices. ${ }^{21-23}$ This approach can help to create materials with low-energy electronic transitions based on donor-acceptor interactions. ${ }^{24-26}$ In this context, Kim and Navarette designed and synthesized a series of D- $\pi$-D and D- $\pi$-A type molecules base on the DTT unit for nonlinear optical materials. ${ }^{27-28}$ They also provided some desirable strategies to access further materials with this type of motif. ${ }^{29-31}$ This goal can be achieved by extending the degree of $\pi$ conjugation within the materials, which affords smaller band gaps. Thus, there is substantial interest in the synthesis and photophysical properties of new families of planar structures with $\pi$ conjugated pure-blue light-emitting molecules. Specifically, 6-bis(arylethynyl) substituted DTT derivatives are of interest. In these compounds, the $\pi$-functionalized phenylacetylene groups were successfully introduced into the thiophene core at the 2,6-positions to afford planar conjugated structures by employing a modified Sonogashira coupling reaction. The introduction of the phenylacetylene groups is expected to extend the conjugation of the thiophene chromophore. This results in a shift of the wavelength of absorption and fluorescence emission into the pure blue visible region of the electromagnetic spectrum 


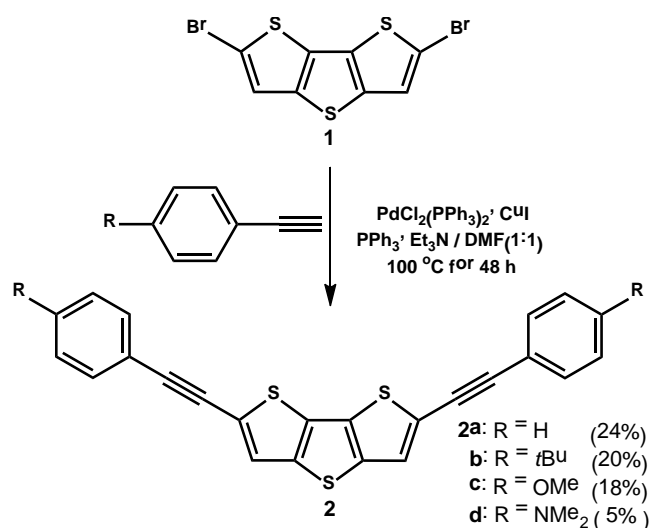

Scheme 1. Synthesis of 2,6-bis(arylethynyl) substituted DTT derivatives 2.

and an improvement of the fluorescence quantum yields. In this paper, we report the synthesis of four types of dithienothiophene derivatives that combine the high hole mobility function of diarylethynyl substituents with the high efficiency and hole-injection ability of dithienothiophene as the conjugation core.

This was achieved by using a Pd-catalysed Sonogashira coupling reaction (Scheme 1). In addition, the synthesis of four $\mathrm{D}-\pi$-D chromophores 2 starting from dithieno[3,2$\left.b: 2^{\prime}, 3^{\prime}-d\right]$ thiophene is also described. ${ }^{32}$ Moreover, the photophysical properties of these compounds are examined in solution through spectroscopic techniques, and this is supported with density functional theory (DFT) calculations.

\section{Results and discussion}

\subsection{Synthesis and characterization}

2,6-Dibromodithieno[3,2-b:2',3'-d]thiophene $\mathbf{1}$ was prepared by brominating dithieno[3,2-b:2',3'-d]thiophene (DTT) with $N$-bromosuccinimide (NBS) in acetic acid at room temperature for $2 \mathrm{~h}$ according to the previously reported procedure. ${ }^{33}$ The Pd-catalysed Sonogashira crosscoupling reactions were carried out between the 2,6dibromodithieno[3,2-b:2',3'-d]thiophene $\mathbf{1}$ and the phenylacetylenes under the modified reaction conditions ${ }^{34-35}$ to afford the target 2,6-bis(arylethynyl)-substituted dithieno[3,2-b:2',3'-d]thiophenes $2 \mathbf{a}-\mathbf{d}$ in moderate yield. (Scheme 1).

The structures of these novel planar $\pi$-conjugated compounds $\mathbf{2 a - d}$ were fully characterized on the basis of ${ }^{1} \mathrm{H}-\mathrm{NMR},{ }^{13} \mathrm{C}-\mathrm{NMR}$ spectra (see Figure $\mathrm{S} 1-8$ in the Supporting Information). ${ }^{36-37}$ Simultaneously, the structures of $\mathbf{2 a - d}$ were further established on the basis of the base peak molecular ion at $\mathrm{m} / \mathrm{z}\left[\mathrm{M}^{+}\right] 369.00$ for $\mathbf{2 a}, 508.11$ for $\mathbf{2 b}$, 456.04 for 2c and 482.13 for $2 \mathbf{d}$ in their mass spectra. All results were consistent with the proposed structures. These four bis(arylethynyl)-functionalized dithieno[3,2-b:2',3'd] thiophenes $\mathbf{2 a}-\mathbf{d}$ are very stable solids with colours from orange to red that can be kept in air for prolonged periods of time at room temperature. All $\pi$-extended molecules are noteworthy for its good solubility in organic solvents.

A single crystal of 2c, suitable for X-ray diffraction studies, was obtained by slow evaporation of solvents from a mixture of $\mathrm{CH}_{2} \mathrm{Cl}_{2}$ and hexane (3:2) at room temperature. From the X-ray diffraction studies, the extended $\pi$-conjugation of the dithieno[3,2-b:2',3'-d] thiophene derivative 2c (Figure 1a) was revealed which lies on a mirror plane. From the packing pattern, a supramolecular network was constructed via a number of complicated intermolecular interactions. As a representative

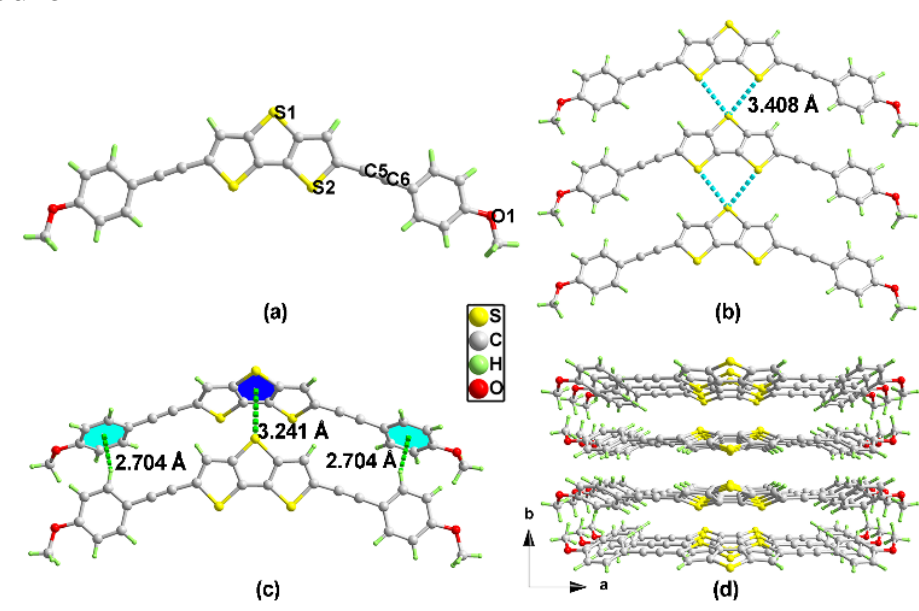

Figure 1. (a) Crystal structure of 2c; (b), (c) detailed interactions between the neighbouring DTT molecules; (d) an overall view of the stacking of the selfassembly parallel to the $c$ axis.

example, there are S1 $\cdots$ S2 i nteractions at $3.408 \AA$ giving rise to chains parallel to the $c$ axis (Figure 1b). These chains then stack parallel to the $b$ axis, and no significant $\pi$ - $\pi$ stacking interactions between the pyrene rings were observed. However, there are two different kinds of interactions based on the planar $\pi$-conjugated thiophene and $\mathrm{C}_{6}$ aromatic ring, namely: 1) $\mathrm{C}-\mathrm{H} \cdots \pi$ interaction of the donor group with the $\mathrm{C}_{6}$ aromatic ring (blue pane), where the $\mathrm{C}-\mathrm{H} \cdots \pi$ distance is $2.704 \AA$; and 2 ) an $\mathrm{S} \cdots \pi$ interaction of the $S$ atom with the thiophene ring of the neighbouring molecules (dark blue pane) at a distance of 3.241 $\AA$ (Figure 1c). These intermolecular interactions increase the effective dimensionality of the electronic structure and are beneficial to charge transport (Figure 1d). The DTT core adopt planar conformation, and the mean tilt angle between the two molecular planes is $43.3^{\circ}$. Interestingly, 2,6distyryldithieno[3,2-b:2',3'-d]thiophene, which feature a transtrans configuration between the double bonds, possesses a mean tilt angle of $37.1^{3 .}{ }^{38}$ Consequently, it is beneficial to efficiently reducing $\pi-\pi$ interactions and aggregation-caused quenching with the increasing of the tilt angle. This suggest these chromophores can be as good candidates of the phosphorescent organic lightemitting diodes. ${ }^{39-41}$

\subsection{Photo-physical properties}

The UV-vis absorption and fluorescence spectra of these four types of 2,6-bis(arylethynyl)-substituted dithieno[3,2$\left.b: 2^{\prime}, 3^{\prime}-d\right]$ thiophenes $\mathbf{2 a - d}$ were measured in dilute dichloromethane and the optical data is summarized in Table 1. Compared with the value for the parent compound DTT at $291 \mathrm{~nm}$, the maximum absorption wavelength of the D- $\pi$-D DTT derivatives 2 is observed more than $c a .95 \mathrm{~nm}$ redshifted to 386 (2a), 390 (2b), 392 (2c), and 415 (2d). As expected, the molecular geometries of the $\mathrm{D}-\pi$-D structures have an impact on the optical properties primarily due to intramolecular charge transfer (ICT). On the other hand, for the UV/vis absorption spectra of $\mathbf{2 a}-\mathbf{c}$, the profiles of these spectra are almost identical and the absorption bands are observed in the range 340-430 nm (Figure 2a), which exhibited a large number of transition bands.

The fluorescence spectra of $\mathbf{2 a - c}$ exhibited a sharp peak at $\lambda_{\text {em max }}=421,424$, and $429 \mathrm{~nm}$ with a shoulder, respectively. The emission spectrum of $\mathbf{2 d}$ displays a single broad peak at $484 \mathrm{~nm}$, which indicates that the emission occurs from the lowest excited state with the largest oscillator strength. With the increasing the $\pi$-conjugation, 
Table 1. Photo-physical properties of compounds 2 and DTT.

\begin{tabular}{|c|c|c|c|c|c|c|c|}
\hline \multirow{2}{*}{ Compounds } & \multicolumn{2}{|c|}{$\lambda_{\text {mav }}$ abs[nm] } & \multicolumn{2}{|c|}{$\lambda_{\text {mav }} \mathrm{PL}[\mathrm{nm}]^{[\mathrm{c}]}$} & \multicolumn{2}{|c|}{$\begin{array}{c}\text { Stokes-shift } \\
{[\mathrm{nm}]}\end{array}$} & \multirow{2}{*}{$\Phi_{f}^{[\mathrm{d}]}$} \\
\hline & Sol. ${ }^{[\mathrm{a}]}$ & Film $^{[b]}$ & Sol. ${ }^{[a]}$ & Film $^{[b]}$ & Sol. ${ }^{[\mathrm{a}]}$ & Film $^{[b]}$ & \\
\hline $2 a$ & 386 & 383 & 421 & 541 & 35 & 158 & 0.41 \\
\hline $2 b$ & 390 & 385 & 424 & 498 & 34 & 113 & 0.47 \\
\hline $2 c$ & 392 & 388 & 429 & 537 & 37 & 149 & 0.48 \\
\hline 2d & 415 & 430 & 484 & 539 & 69 & 109 & 0.57 \\
\hline DTT & 291 & $\mathrm{nd}^{[\mathrm{e}]}$ & 374 & nd & 83 & nd & 0.01 \\
\hline
\end{tabular}

${ }^{[\mathrm{a}]}$ Measured in dichloromethane at room temperature.

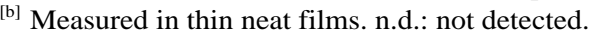

[c] PL: photoluminescence. The values in parentheses are the excitation wavelengths.

${ }^{\mathrm{d}}$ Absolute quantum yield in $\mathrm{CH}_{2} \mathrm{Cl}_{2}$ at $\sim \times 10^{-6} \mathrm{M}$.

end: not detect.

a gradual bathochromic shift in the $\lambda_{\text {em } \max }$ is clearly observed in the order $\mathbf{2 a}<\mathbf{2} \mathbf{b} \approx \mathbf{2} \mathbf{c}<\mathbf{2 d}$, implying that the energy gap between the ground and the excited states decreases in this order. In this process, the ICT plays an important role in lowering the energy gap. ${ }^{42-45}$ The quantum yields ( $\Phi=0.41$ to $\Phi=0.57$ ) of the compounds 2 show higher than compound $1(\Phi=0.01)$ with the electron-donating ability of the functional group para to the benzene. We also find that there are slight differences, in this process, this was thought to be the ICT plays an important role in lowering the energy gap.

Synchronously, we also obtained the UV-Vis absorption spectra and emission spectra of $\mathbf{2 a - d}$ in thin neat films (see Figure S9 in the Supporting Information), and the corresponding data are summarized in Table 1 . We noted that the four DTT-based molecules displayed slight bathochromic and hypsochromic shift. Interestingly, those compounds as films exhibited significant bathochromic phenomena, and displayed $\lambda_{\text {film, max }}$ values of $541 \mathrm{~nm}, 498 \mathrm{~nm}$, $537 \mathrm{~nm}$, and $539 \mathrm{~nm}$, respectively, and compared with their corresponding emission spectra in solution, and red-shift range is $55-120 \mathrm{~nm}$ (120 nm for $\mathbf{2 a}, 74 \mathrm{~nm}$ for $\mathbf{2 b}, 108 \mathrm{~nm}$ for $\mathbf{2 c}$, and $55 \mathrm{~nm}$ for $\mathbf{2 d}$, respectively). These results are probably due to the planar $\pi$-conjugation structures that tend to form dimers.

The concentration dependent fluorescent measurement of compounds 2 were investigated, and the emission intensity increased with the increasing of the solutions. Figure 3 shows the fluorescence emission spectra of compound $\mathbf{2 b}$ and the concentration effect in dichloromethane at room temperature. On increasing the concentration of $\mathbf{2} \mathbf{b}$ from 1.0 $\times 10^{-8} \mathrm{M}$ (line 1 ) to $1.0 \times 10^{-4} \mathrm{M}$ (line 9 ), the corresponding emission at $429 \mathrm{~nm}$ was observed for the monomer unit, and the intensity of this emission band gradually increased. The reason is likely associated with the sterically hindered substituents (the two bulky tert-butyl groups) at the 2,6positions in $\mathbf{2 b}$ which play an important role for inhibiting the close face-to-face stacking interaction between the neighbouring DTT units; this is consistent with the crystallographic results for $\mathbf{2 c}$.

In order to obtain more insight into of the photo-physical properties of these new coplanar-shaped conjugation compounds, the normalized absorption spectra and the emission spectra of compound $\mathbf{2}$ in various solvent systems were determined, and all of the compounds exhibited almost identical regular changes. So we summarized the optical data of $\mathbf{2 d}$ in Table 2 as a representative. It is well-known that solvatochromic effects not only depend on molecular structure, but also depend on the nature of the chromophore, as well as the solvents. ${ }^{46}$ Each monomer exhibited slight solvatochromism in the absorption
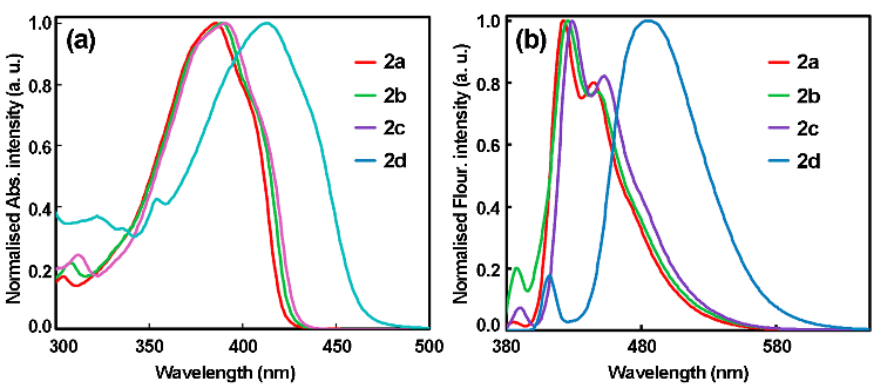

Figure 2. (a) Normalized UV-vis absorption and (b) fluorescence emission spectra of compounds 2 recorded in dichloromethane solutions at $\sim 10^{-5}-10^{-7}$ $\mathrm{M}$ at $25^{\circ} \mathrm{C}$.

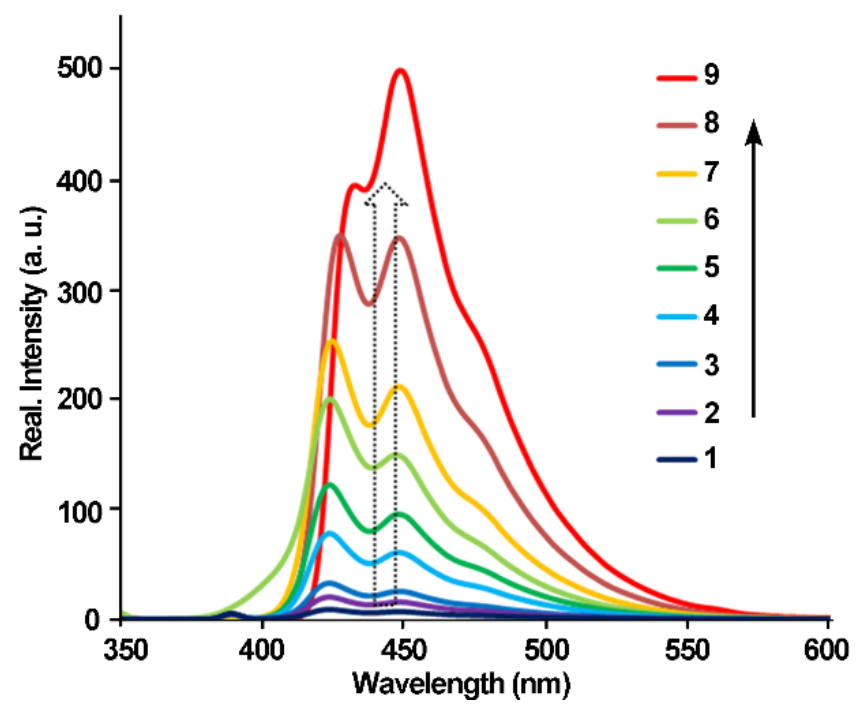

Figure 3. Effect of concentration on the fluorescence emission spectra of $\mathbf{2 b}$ recorded in $\mathrm{CH}_{2} \mathrm{Cl}_{2}$ at $25^{\circ} \mathrm{C}$. (1) $1.0 \times 10^{-8} \mathrm{M}$, (2) $2.5 \times 10^{-8} \mathrm{M}$, (3) $1.0 \times 10^{-7}$ $\mathrm{M}$, (4) $2.5 \times 10^{-7} \mathrm{M}$, (5) $1.0 \times 10^{-6}$, (6) $2.5 \times 10^{-6} \mathrm{M}$, (7) $5.0 \times 10^{-6} \mathrm{M}$, (8) 2.5 $\times 10^{-5} \mathrm{M}$, (9) $1.0 \times 10^{-4} \mathrm{M}$.

spectra and emission spectra. For 2d, a change of solvent from nonpolar cyclohexane to polar DMF caused only a very slight (positive) bathochromic shift with the $\pi-\pi^{*}$ absorption band moving from 410 to $415 \mathrm{~nm}$. On the other hand, in the case of the emission spectra of $\mathbf{2 d}$, we observed a substantial positive bathochromic shift with a peak at around $446 \mathrm{~nm}$ in cyclohexane, whilst a broad and red-shifted emission with only one peak at $515 \mathrm{~nm}$ was observed in the highly polar solvent DMF (Figure 4). Such large Stokes' shift observed for $\mathbf{2 d}$ in polar solvents may result from the difference of the dipole moments between the delocalized ground state and the highly localized excited state. The highly localized excited state must arise from the intramolecular charge transfer (ICT) between the $\mathrm{NMe}_{2}$ group and the thiophene core. ${ }^{47-49}$ The relationship between the Stokes' shift and the difference in the dipole moments can be related by the Lippert-Mataga equation:

$$
\begin{aligned}
& \Delta v=2 \Delta \mu_{e g}^{2} \Delta f / h c a^{3}+\text { const } \\
& \Delta f=[(\varepsilon-1) /(2 \varepsilon+1)]-\left[\left(n^{2}-1\right) /\left(2 n^{2}+1\right)\right](2)
\end{aligned}
$$

where $\Delta v$ and $\Delta \mu_{e g}$, are Stokes' shift and the difference in the dipole moment between the excited and ground states, respectively; $\Delta f$ is the orientation polarizability; $h$ is Planck's constant; $c$ is the velocity of light; $a$ is the Onsager radius around a fluorophore; $\varepsilon$ is the dielectric constant; $n$ is refractive index. ${ }^{50-}$

${ }^{51}$ To calculate $\Delta \mu_{e g}$, the Stokes' shifts for $\mathbf{2 d}$ were plotted against the $\Delta f$ values in the solvents 1,4-dioxane, cyclohexane, THF, 

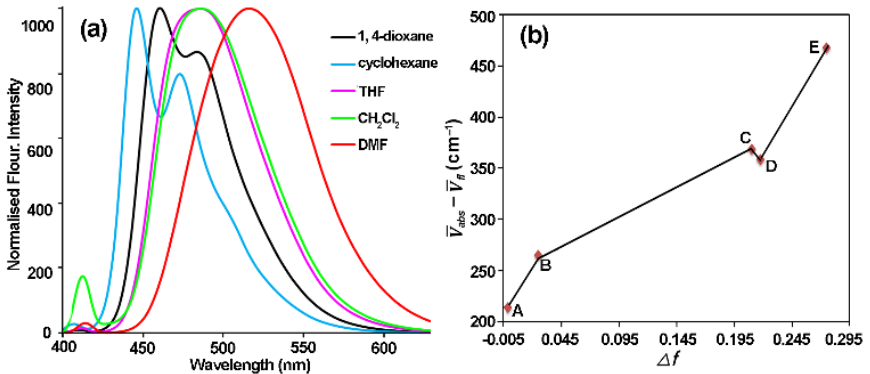

Figure 4. (a), (b) Normalized fluorescence spectra and Lippert-Mataga plots of compound 2d recorded in (A) 1, 4-dioxane, (B) Cyclohexane, (C) THF, (D) $\mathrm{CH}_{2} \mathrm{Cl}_{2}$, and (E) DMF at $25^{\circ} \mathrm{C}$.

Table 2. Optical absorption and emission spectroscopic data for $\mathbf{2 d}$ in various solvents at room temperature. ${ }^{\text {[a] }}$

\begin{tabular}{|c|c|c|c|c|}
\hline Compound & Solvent & $\begin{array}{c}\text { Absorption }^{[b]} \\
\lambda_{\mathrm{abs}}[\mathrm{nm}] \\
\end{array}$ & $\begin{array}{l}\text { Fluorescence } \\
\lambda_{\max }[\mathrm{nm}]\left(\lambda_{\mathrm{ex}}\right)^{[c]}\end{array}$ & $\Phi_{f}^{[d]}$ \\
\hline \multirow{5}{*}{ 2d } & 1, 4-Dioxane & 410 & 460 & 0.44 \\
\hline & Cyclohexane & 407 & 446 & 0.47 \\
\hline & THF & 412 & 486 & 0.42 \\
\hline & $\mathrm{CH}_{2} \mathrm{Cl}_{2}$ & 415 & 484 & 0.57 \\
\hline & $\mathrm{DMF}$ & 415 & 515 & 0.62 \\
\hline
\end{tabular}

${ }^{[\mathrm{a}]}$ All measurements were performed under degassed conditions.

${ }^{[b]} \sim \times 10^{-5} \mathrm{M}$ in the different solvents, $\lambda_{\mathrm{abs}}$ is the absorption band appearing at the longest wavelength.

${ }^{[\mathrm{c}]} \sim \times 10^{-7} \mathrm{M}$ in the different solvents, $\lambda_{\mathrm{ex}}$ is the fluorescence band appearing at the shortest wavelength.

[d] Fluorescence quantum yields.

$\mathrm{CH}_{2} \mathrm{Cl}_{2}$ and DMF (Figure 4). According to the Lippert-Mataga equation, the $\Delta \mu_{e g}$ value for $\mathbf{2 d}$ was estimated to be $c a .30 \mathrm{D}$ (from the slope), meaning that the dipole moment of $\mathbf{2 d}$ drastically changed from the ground to the excited states. On the basis of the large $\Delta \mu_{e g}$ value and the DFT analysis for the ground states, one might suppose that charge separation can exist only in the excited states of the donor-modified $\pi$-extended dithienothiophene. The Lippert-Mataga plot for the various solvents used in this study also gave a relatively good correlation between the Stokes' shifts of $\mathbf{2 d}$ and their $\Delta f$ values. The thiophene core in $\mathbf{2 d}$ can behave as an acceptor moiety against the dimethylamino groups to increase the fluorescence solvatochromicity probability based on the ICT mechanism. As expected, the findings obtained from UV/vis and fluorescence spectra and Lippert-Mataga analysis imply that the charge separation arises in the excited states of the donor-modified $\mathbf{2 d}$.

\subsection{Quantum chemistry calculations}

To reinforce the ICT mechanism, DFT calculations for 2 were performed to understand the electronic structures of the D- $\pi$-D compounds at the B3LYP/6-31G+(d) level. In particular, the effect of the introduction of donor moieties onto the $\pi$-extended DTT. The optimized molecular geometries and frontier molecular orbitals of the four DTT-based derivatives for the DTT core are illustrated in Figure 5. In this model, the HOMOs of the compounds $\mathbf{2}$ are almost spread over the entire molecular skeleton, while the LUMOs are mostly distributed over the $\pi$ center, including the DTT core and the side triple bonds onto the DTT unit. Compared with the DTT unit, the separated LUMOs resulted from the electron-donating nature of the phenyl groups. The gradually increasing HOMO energy levels were delocalized onto the backbone, implying that the electrons were delocalized by the introduction of the conjugated side chain. The resulting extension of the side chain conjugation decreased the bandgap of the DTT derivatives resulting in the improved absorption of light at longer wavelengths, consistent with the photo-physical properties results.

\section{Conclusion}

In this work, we designed and synthesized four symmetric D$\pi$-D type molecules via Sonogashira coupling reaction with DTT and various kinds of $p$-substituted phenylacetylenes under mild reaction conditions. Those DTT-based derivatives $\mathbf{2}$, with planar $\pi$-extended conjugated structures were fully characterized. The HOMO-LUMO gap was diminished by an increase in the HOMO orbital energy and decrease in the LUMO orbital energy, which led to remarkable intermolecular charge-transfer (ICT). The results were verified through inspecting the absorption and emission spectra of compounds 2, for which obvious red-shifts were observed both in the solutions and in the solid state. Given these results, these compounds are promising as blue organic light-emitting materials for the fabrication of OLED devices. More remarkable, the $\mathrm{D}-\pi$-D organic molecules with sufficient conjugation to form a delocalized HOMO of suitable energy level for a p-type organic semiconductor, as well as solar cell. And further detailed investigations aimed at developing this applied research is ongoing in our group.

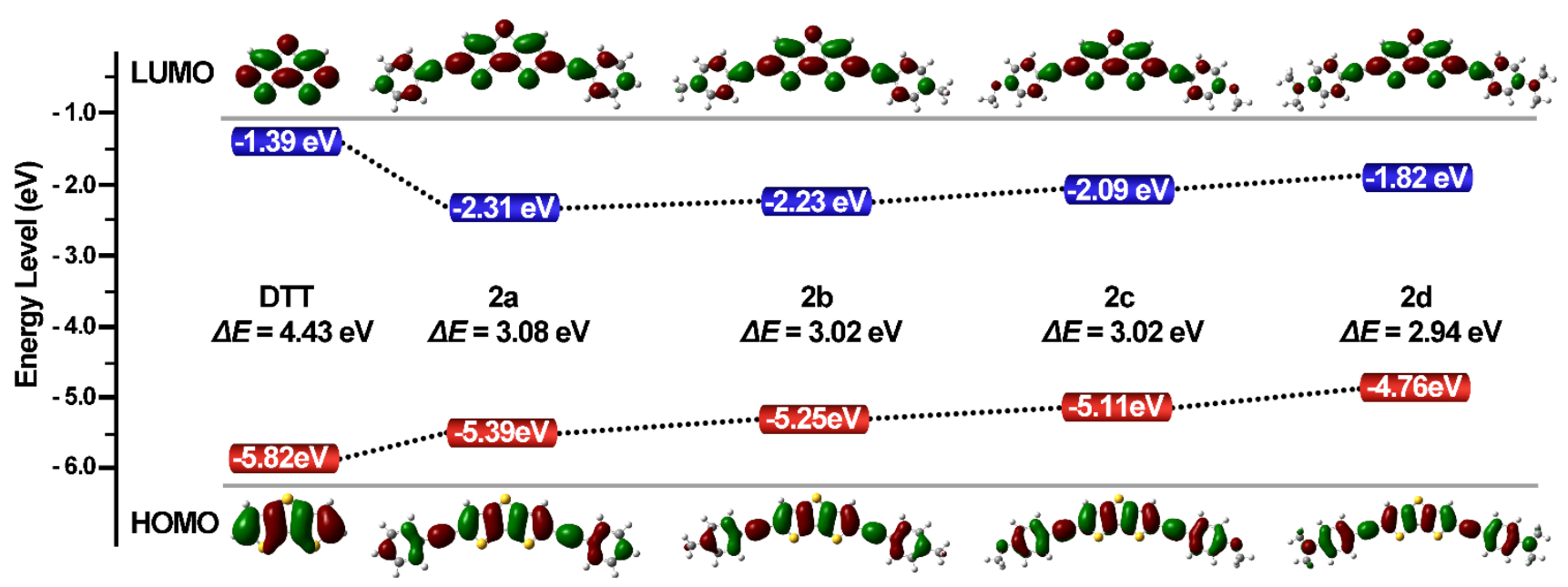

Figure 5. HOMO/LUMO energy levels and frontier molecular orbitals obtained from DFT calculations on the DTT and compounds 2 with optimized geometries. $\triangle E$ is an energy bandgap of the DTT and compounds 2 estimated from difference between the HOMO and LUMO values. 


\section{Experimental section}

${ }^{1} \mathrm{H} /{ }^{13} \mathrm{C}$ NMR spectra were recorded at $300 \mathrm{MHz}$ and 75 $\mathrm{MHz}$ on a Nippon Denshi JEOL FT-300 NMR spectrometer in deuteriochloroform with $\mathrm{Me}_{4} \mathrm{Si}$ as an internal reference. Mass spectra were obtained on a Nippon Denshi JMSHX110A Ultrahigh Performance Mass Spectrometer at 75 $\mathrm{eV}$ using a direct-inlet system. Elemental analyses were performed by Yanaco MT-5. UV-vis spectra were recorded on a Perkin Elmer Lambda 19 UV/VIS/NIR spectrometer. Emission spectra were performed in a semimicro fluorescence cell $\left(\right.$ Hellma $^{\circledR}$, 104F-QS, $10 \times 4$ mm, $1400 \mu \mathrm{L}$ ) with a Varian Cary Eclipse spectrophotometer. Gas-liquid;

chromatograph (GLC) analyses were performed by Shimadzu gas chromatograph, GC-14A; silicone OV-1, 2 m programmed temperature rise, $12{ }^{\circ} \mathrm{C} \mathrm{min}^{-1}$; carrier gas

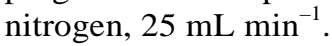

\subsection{Synthesis of 2,6-bis(phenylethynyl)dithieno[3,2-b:2',3'- d] thiophene (2a)}

2,6-Dibromodithieno[3,2-b:2',3'-d]thiophene $\quad \mathbf{( 1}^{33} \quad$ (150 $\mathrm{mg}, 0.424 \mathrm{mmol})$, phenylacetylene $(0.15 \mathrm{~mL}, 1.37 \mathrm{mmol})$, $\mathrm{Pd}\left(\mathrm{PPh}_{3}\right)_{4}$ (30 mg, $\left.0.043 \mathrm{mmol}\right), \mathrm{PPh}_{3}(22.3 \mathrm{mg}, 0.086$ $\mathrm{mmol}), \mathrm{Et}_{3} \mathrm{~N}$ (7.5 mL), CuI (20 mg, $0.106 \mathrm{mmol}$ ) and DMF $(7.5 \mathrm{ml})$ were mixed together and heated at $100{ }^{\circ} \mathrm{C}$ for $78 \mathrm{~h}$ in a Schlenk tube equipped with a magnetic stirring bar and a reflux condenser under $\mathrm{N}_{2}$ atmosphere. The reaction was quenched with saturated solution of ammonium chloride (30 $\mathrm{mL})$ and extracted with $\mathrm{CHCl}_{3}(100 \mathrm{~mL})$ three times. Then, the combined organic phase was washed with brine, and dried over $\mathrm{MgSO}_{4}$. Evaporation of the solvent under vacuum resulted in a solid residue. The residue was adsorbed in silica gel (Wako gel, C-300) and purified by column chromatography using hexane as eluent and recrystallization from hexane afforded the desired compound $\mathbf{2 a}$ as yellow prisms (40 mg, 24\%); m.p. $153{ }^{\circ} \mathrm{C}$; $\delta_{\mathrm{H}}\left(\mathrm{CDCl}_{3}\right) 7.36-7.39$ $(6 \mathrm{H}, \mathrm{m}, \mathrm{Ar}-\mathrm{H}), 7.46(2 \mathrm{H}, \mathrm{s}, \mathrm{Ar}-\mathrm{H})$ and $7.54-7.56(4 \mathrm{H}, \mathrm{m}$, $\mathrm{Ar}-H) ; \delta_{\mathrm{C}}\left(\mathrm{CDCl}_{3}\right)$ 83.05, 95.02, 122.55, 124.27, 125.15, 128.46, 128.74, 131.48, 141.75, 170.61; MS: $\mathrm{m} / \mathrm{z}: 369.00$ $\left[\mathrm{M}^{+}\right] . \mathrm{C}_{24} \mathrm{H}_{12} \mathrm{~S}_{3}$ (369.55): Anal. Calcd for C 72.69, H 3.05; Found C 72.41, H 3.08.

4.2. Synthesis of 2,6-bis(4-tert-butylphenylethynyl)dithieno[3,2$b: 2$ ',3'-d] thiophene (2b)

Similarly, 2,6-bis(4-tert-butylphenylethynyl)dithieno[3,2$\left.b: 2^{\prime}, 3^{\prime}-d\right]$ thiophene (2b) was obtained in $20 \%$ yield as yellow needles (hexane); m.p. $187^{\circ} \mathrm{C} ; \delta_{\mathrm{H}}\left(\mathrm{CDCl}_{3}\right) 1.33(18 \mathrm{H}, \mathrm{s}, t-$ $\mathrm{Bu}), 7.39(4 \mathrm{H}, \mathrm{d}, J=8.4 \mathrm{~Hz}, \mathrm{Ar}-H), 7.43(2 \mathrm{H}, \mathrm{s}, \mathrm{Ar}-H)$ and $7.48(4 \mathrm{H}, \mathrm{d}, J=8.4 \mathrm{~Hz}, \mathrm{Ar}-H) ; \delta_{\mathrm{C}}\left(\mathrm{CDCl}_{3}\right) 29.71,40.17$, 109.161, 111.81, 124.01, 132.73 and 150.4; MS: $\mathrm{m} / \mathrm{z}: 508.11$ $\left[\mathrm{M}^{+}\right] . \mathrm{C}_{32} \mathrm{H}_{28} \mathrm{~S}_{3}$ (508.76): Anal. Calcd for C 75.54, H 5.55; Found C 75.66, H 5.43.

4.3. Synthesis of 2,6-bis(4-methoxyphenylethynyl)dithieno[3,2$\left.b: 2^{\prime}, 3^{\prime}-d\right]$ thiophene $(2 c)$

Similarly, 2,6-bis(4-methoxyphenylethynyl)dithieno[3,2$\left.b: 2^{\prime}, 3^{\prime}-d\right]$ thiophene (2c) was obtained in $18 \%$ yield as yellow needles (hexane); m.p. $157{ }^{\circ} \mathrm{C}$; $\delta_{\mathrm{H}}\left(\mathrm{CDCl}_{3}\right) 3.84(6 \mathrm{H}, \mathrm{s}$, OMe), $6.90(4 \mathrm{H}, \mathrm{d}, J=8.8 \mathrm{~Hz}, \operatorname{Ar}-H), 7.41(2 \mathrm{H}, \mathrm{s}, \mathrm{Ar}-H)$ and $7.48(4 \mathrm{H}, \mathrm{d}, J=8.8 \mathrm{~Hz}, \mathrm{Ar}-H) ; \delta_{\mathrm{C}}\left(\mathrm{CDCl}_{3}\right) 55.35,81.83$, 95.04, 114.16, 114.64, 124.58, 124.67, 131.09, 133.05, 141.50 and 160.05; MS: $\mathrm{m} / \mathrm{z}$ : $456.04 \quad\left[\mathrm{M}^{+}\right] . \quad \mathrm{C}_{26} \mathrm{H}_{16} \mathrm{~S}_{3}$ (456.60): Anal. Calcd for C 68.39, H 3.53; Found C 68.14, H 3.54 .
4.4. Synthesis of 2,6-bis[(4-dimethylamino)phenylethynyl]dithieno[3,2-b:2',3'-d] thiophene (2d)

Similarly, 2,6-bis[(4-dimethylamino)phenylethynyl]dithieno[3,2-b:2',3'-d]thiophene (2d) was obtained in 5\% yield as reddish-brown prisms $\left(\mathrm{CHCl}_{3}\right)$; m.p. $255{ }^{\circ} \mathrm{C} ; \delta_{\mathrm{H}}$ $\left(\mathrm{CDCl}_{3}\right) 3.01(12 \mathrm{H}, \mathrm{s}, \mathrm{Me}), 6.67(4 \mathrm{H}, \mathrm{d}, J=8.8 \mathrm{~Hz}, \mathrm{Ar}-H)$, $7.36(2 \mathrm{H}, \mathrm{s}, \mathrm{Ar}-H)$ and $7.41(4 \mathrm{H}, \mathrm{d}, J=8.8 \mathrm{~Hz}, \mathrm{Ar}-H) ; \delta_{\mathrm{C}}$ $\left(\mathrm{CDCl}_{3}\right)$ 29.71, 40.17, 109.16, 111.81, 124.01, 132.73 and 150.39; MS: $\mathrm{m} / \mathrm{z}$ : $482.13\left[\mathrm{M}^{+}\right] . \mathrm{C}_{28} \mathrm{H}_{22} \mathrm{~S}_{3}$ (482.69): Anal. Calcd for C 69.67, H 4.59, N 5.80; Found C 69.54, H 4.54, N 5.72.

\subsection{Single-crystal $X$-ray diffraction measurements}

A suitable single crystal $\left(0.96 \times 0.24 \times 0.03 \mathrm{~mm}^{3}\right)$ was mounted on a Bruker APEX 2 CCD diffractometer equipped with fine-focus $\operatorname{MoK} \alpha(\lambda=0.71073 \AA)$ sealed tube radiation source for 2c. ${ }^{52}$ Detailed crystallographic data for $\mathbf{2 c}$ : $\mathrm{C}_{26} \mathrm{H}_{16} \mathrm{O}_{2} \mathrm{~S}_{3}, \quad \mathrm{M}=456.57$, orthorhombic, Pmc2 $2_{1}, \quad a=$ 50.008(18), $b=7.318(3), c=5.954(2) \AA, V=2178.9$ (14) $\AA^{3}, Z=4, D_{\mathrm{c}}=1.392 \mathrm{~g} / \mathrm{cm}^{3}, T=150(2) \mathrm{K}$, yellow lath; 9611 reflections measured of which 2715 were independent; data corrected for absorption on the basis of symmetry equivalent and repeated data (min and max transmission factors: 0.723 and 0.989 ) and Lp effects, $R_{\text {int }}=0.042$, structure solved by direct methods, ${ }^{53} F^{2}$ refinement, ${ }^{54} R_{1}=0.032$ for 2360 data with $F^{2}>2 \sigma\left(F^{2}\right), w R_{2}=0.078$ for all data, 174 parameters. CCDC 1497723 contains the supplementary crystallographic data for this paper. These data can be obtained free of charge from The Cambridge Crystallographic Data Centre via www.ccdc.cam.ac.uk/data_request/cif.

\section{Acknowledgments}

This work was performed under the Cooperative Research Program of "Network Joint Research Center for Materials and Devices (Institute for Materials Chemistry and Engineering, Kyushu University)”. We would like to thank the OTEC at Saga University and the International Cooperation Projects of Guizhou Province (No. 20137002), The Royal Society of Chemistry for financial support and the EPSRC is thanked for an overseas travel grant to C.R.

\section{Supplementary data}

Electronic Supplementary Information (ESI) available: Details of single-crystal X-ray crystallographic data. ${ }^{1} \mathrm{H},{ }^{13} \mathrm{C}$ NMR of 2, and Cartesian coordinates of all optimized structures for originality of the computation results. For ESI and other electronic format see DOI: 10.1039/x0xx00000x

\section{References and notes}

1. Jradi, F. M.; Kang, X. W.; O’Neil, D.; Pajares, G.; Getmanenko, Y. A.; Szymanski, P.; Parker, T. C.; El-Sayed, M. A.; Marder, S. R. Chem. Mater. 2015, 27, 2480-2487.

2. Zhang, S. H.; Zuo, L. J.; Chen, J. H.; Zhang, Z. Q.; Mai, J. Q.; Lau. T.K.; Lu, X. H.; Shi, M. M.; Chen, H. Z. J. Mater. Chem. A 2016, 4, 1702-1707.

3. Wu, W.; Liu, Y.; Zhu, D. Chem. Soc. Rev. 2010, 39, 1489-1502.

4. Sun, H. L.; Shi, J. W.; Zhang, Z. L.; Zhang, S.; Liang, Z. L.; Wan, S. S.; Cheng, Y. X.; Wang, H. J. Org. Chem. 2013, 78, 6271-6275.

5. Huang, J. M.; Ie, Y.; Karakawa, M.; Saito, M.; Osaka, I.; Aso, Y. Chem. Mater. 2014, 26, 6971-6978. 
6. Chang, S. W.; Kettle, J.; Waters, H.; Horie, M. RSC Adv. 2015, 5, 107276-107284.

7. Yamamoto, T.; Nishimura, T.; Mori, T.; Miyazaki, E.; Osaka, I.; Takimiya, K. org. Lett. 2012, 14, 4914-4917.

8. Nakano, M.; Niimi, K.; Miyazaki, E.; Osaka, I.; Takimiya, K., J. Org. Chem. 2012, 77, 8099-8111.

9. Ozturk, T.; Ertas, E.; Mert, O. Tetrahedron 2005, 61, 11055-11077.

10. Viola, I.; Piliego, C.; Favaretto, L.; Barbarella, G.; Cingolani, R.; Gigli, G. ACS Appl. Mater. Interfaces 2010, 2, 484-490.

11. Mishra, A.; Ma, C. Q.; Bäuerle, P. Chem. Rev. 2009, 109, 1141-1276.

12. Aragó, J.; Viruela, P. M.; Gierschner, J.; Ortí, E.; Milián-Medina, B. Phys. Chem. Chem. Phys. 2011, 13, 1457-1465.

13. Roncali, J. Chem. Rev. 1992, 92,711-738.

14. Coropceanu, V.; Cornil, J.; da Silva Filho, D. A.; Olivier, Y.; Silbey, R.; Brédas, J. L. Chem. Rev. 2007, 107, 926-952.

15. Ra, C. S.; Yim, S.; Park, G. Bull. Korean Chem. Soc. 2008, 29, 891893.

16. Takimiya, K.; Shinamura, S.; Osaka, I.; Miyazaki, E. Adv. Mater. 2011, 23, 4347-4370.

17. Jørgensen, M.; Norrman, K.; Gevorgyan, S. A.; Tromholt, T.; Andreasen, B.; Krebs, F. C. Adv. Mater. 2012, 24, 580-612.

18. Jhuo, H. J.; Yeh, P. N.; Liao, S. H.; Li, Y. L.; Cheng, Y. S.; Chen, S. A. J. Chin. Chem. Soc. 2014, 61, 115-126.

19. Cinar, M. E.; Ozturk, T. Chem. Rev. 2015, 115, 3036-3140.

20. Jong, F. De; Janssen, M. J. J. Org. Chem. 1971, 36, 1645-1648.

21. Shibano, Y.; Umeyama, T.; Matano, Y.; Imahori, H. Org. Lett. 2007, 10, 1971-1974.

22. Huang, J. D.; Wen, S. H.; Han, K. L. Chem.-Asian J. 2012, 7, 10321040.

23. Xiong, Y.; Qiao, X. L.; Wu, H. Z.; Huang, Q. L.; Wu, Q. H.; Li, J.; Gao, X. K.; Li, H. X. J. Org. Chem. 2014, 79, 1138-1144.

24. Mazzeo, M.; Vitale, V.; Sala, F. D.; Anni, M.; Barbarella, G.; Fabaretto, L.; Sotgiu, G.; Cingolani, R.; Gigli, G. Adv. Mater. 2005, 17, 34-39.

25. Sala, F. D.; Vitale, V.; Mazzeo, M.; Cingolani, R.; Gigli, G.; Favaretto, L.; Barbarella, G. J. Non-Cryst. Solids 2006, 352, 2461-2464.

26. Liao, Y. L.; Lin, C. Y.; Wong, K. T.; Hou, T. H.; Hung, W. Y. Org. Lett. 2007, 10, 4511-4514.

27. Kim, O. K.; Lee, K. S.; Woo, H. Y.; Kim, K. S.; He, G. S.; Swiatkiewicz, J.; Prasad, P. N. Chem. Mater. 2000, 12, 284-286.

28. Ortiz, R. P.; Delgado, M. C. R.; Casado, J.; Hernández, V.; Kim, O. K.; Woo, H. Y.; Navarrete, J. T. López J. Am. Chem. Soc. 2004, 126 , 13363-13376.

29. Wang, H. K.; Lin, H.; Xu, W.; Zhu, D. B. Chem. Eur. J. 2013, 19, 3366-3373.

30. Chen, L.; Baumgarten, M.; Guo, X.; Li, M.; Marszalek, T.; Alsewailem, F. D.; Pisula, W.; Müllen, K. J. Mater. Chem. C 2014, 2, 3625-3630.
31. Cheng, S. S.; Huang, P. Y.; Ramesh, M.; Chang, H. C.; Chen, L. M.; Yeh, C. M.; Fung, C. L.; Wu, M. C.; Liu, C. C.; Kim, C.; Lin, H. C.; Chen, M. C.; Chu, C. W. Adv. Funct. Mater. 2014, 24, 2057-2063.

32. He, M. Q.; Zhang, F. X. J. Org. Chem. 2007, 72, 442-451.

33. Sotzing, G. A.; Reynolds, J. R.; Steel, P. J. Chem. Mater. 1996, 8, 882889.

34. Hu, J. Y.; Era, M.; Elsegood, M. R. J., Yamato, T. Eur. J. Org. Chem. 2010, 72-79.

35. Hu, J. Y.; Ni, X. L.; Feng, X.; Era, M.; Elsegood, M. R. J.; Teat, S. J.; Yamato, T. Org. Biomol. Chem. 2012, 10, 2255-2262.

36. Li, P.; Ahrens, B.; Feeder, N.; Raithby, P. R.; Teat, S. J.; Khan, M. S. Dalton Trans. 2005, 874-883.

37. Kaida, H.; Satoh, T.; Hirano, K.; Miura, M. Chem. Lett. 2015, 44, $1125-1127$.

38. Liu, Y.; Di, C. A.; Du, C. Y.; Liu, Y. Q.; Lu, K.; Qiu, W. F.; Yu, G. Chem. Eur. J. 2010, 16, 2231-2239.

39. Kavitha, J.; Chang, S. Y.; Chi, Y.; Yu, J. K.; Hu, Y. H.; Chiu, P. T.; Peng, S. M.; Lee, G. H.; Tao, Y. T.; Chien, C. H.; Carty, A. J. Adv. Funct. Mater. 2005, 15, 223-229.

40. Yang, C. L.; Zhang, X. W.; You, H.; Zhu, L. Y.; Chen, L. Q.; Zhu, L. N.; Tao, Y. T.; Ma, D. G.; Shuai, Z. G.; Qin, J. G. Adv. Funct. Mater. 2007, 17, 651-661.

41. Kim, W. J.; Bonoiu, A. C.; Hayakawa, T.; Xia, C.; Kakimoto, M.; Pudavar, H. E.; Lee, K. S.; Prasad, P. N. Int. J. Pharm. 2009, 376, 141-152.

42. Lartia, R.; Allain, C.; Bordeau, G.; Schmidt, F.; Fiorini-Debuisschert, C.; Charra, F.; Teulade-Fichou, M. P. J. Org. Chem. 2008, 73, 17321744.

43. Droumaguet, C. L.; Sourdon, A.; Genin, E.; Mongin, O.; BlanchardDesce, M. Chem. Asian J. 2013, 8, 2984-3001.

44. Karmakar, S.; Maity, D.; Mardanya, S.; Baitalik, S. J. Phys Chem. A 2014, 118, 9397-9410.

45. Chen, X.; Sang, X.; Zhang, Q. RSC Adv. 2015, 5, 53211-53219.

46. Reichardt, C. Chem. Rev. 1994, 94, 2319-2358.

47. Yang, S. W.; Elangovan, A.; Hwang, K. C.; Ho, T. I. J. Phys. Chem. B. 2005, 109, 16628-16635.

48. Adhikari, R. M.; Mondal, R.; Shah, B. K.; Neckers, D. C. J. Org. Chem. 2007, 72, 4727-4732.

49. Feng, X.; Tomiyasu, H.; Hu, J. Y.; Wei, X. F.; Redshawd, C.; Elsegood, M. R. J.; Horsburgh, L.; Teat, S. J.; Yamato, T. J. Org. Chem. 2015, 80, 10973-10978.

50. Mataga, N.; Kaifu, Y.; Koizumi, M. Bull. Chem. Soc. Jpn. 1956, 29, 465-470.

51. Lippert, E. Z. Elektrochem 1957, 61, 962-975.

52. APEX 2 \& SAINT 2012, software for CCD diffractometers. Bruker AXS Inc. Madison, USA.

53. Sheldrick, G.M. Acta Crystallogr. 2008, A64, 112-122.

54. Sheldrick, G. M. Acta Crystallogr. 2015, C71, 3-8. 